\title{
La imposibilidad de la lectura: \\ memoria y trauma en Maldición eterna a quien lea estas páginas, de Manuel Puig
}

\section{The impossibility of reading: memory and trauma in Manuel Puig's Eternal Curse on the Reader of These Pages}

Leonardo Berneri

Universidad Nacional de Rosario

DOI: https://doi.org/10.5902/2176148537190

\begin{abstract}
Resumen: En Maldición eterna a quien lea estas páginas, novela atravesada por la tensión entre lo íntimo y lo político, entre la memoria y el trauma, la ficcionalización de la lectura ocupa un lugar central. La novela está estructurada como un diálogo entre dos personajes, definidos por el olvido y la frustración, que buscan construir, a través de la lectura, el sentido de un mundo que es extraño e inaccesible. La novela narra la necesidad de la lectura como modo de construirse un relato de sí frente a la experiencia traumática, a la vez que expone su imposibilidad.
\end{abstract}

Palabras clave: Manuel Puig. Ficcionalización de la lectura. Dictadura. Memoria. Trauma.

Abstract: In Eternal Curse on the Reader of These Pages, a novel crossed by the tension between the intimate and the political, between memory and trauma, the fictionalization of reading occupies a central place. The novel is structured as a dialogue between two characters, defined by oblivion and frustration, who seek to build, through reading, the meaning of a strange and inaccessible world. The novel narrates the necessity of reading as a way to build a self-narrative against the traumatic experience, while exposing its impossibility.

Keywords: Manuel Puig. Fictionalization of reading. Dictatorship. Memory. Trauma. 
Maldición eterna a quien lea estas páginas probablemente sea la más desesperanzada y amarga de las novelas de Manuel Puig. La tensión entre lo íntimo y lo político, entre la memoria y la experiencia traumática en el contexto de la última dictadura militar argentina la atraviesa y la estructura al relacionarse con la lectura. En la literatura de Puig, la ficcionalización de la lectura, esto es, los momentos en que la lectura de todo tipo de textos aparece representada, rememorada o referida, ocupa un lugar central cuyo punto cúlmine es esta novela, donde la lectura alcanza dimensiones nuevas. Escrita en 1980, Maldición eterna... es, muy

Leonardo

Berneri probablemente, la primera novela en tematizar de un modo explícito la dictadura cívico-militar argentina y abre así la serie de novelas sobre la dictadura, serie todavía no cerrada ${ }^{1}$. Se trata de una novela que pone el dedo en la llaga de la historia. A través de Ramírez, ese personaje lastimoso e insufrible a la vez, ese sujeto despojado y expuesto en la fragilidad de sus últimos días, Puig descubre un abismo de sangre y derrotas, la grieta insalvable del horror que quiebra el tiempo, y se sumerge en ella sin respuestas.

Ramírez, un anciano de 74 años, se encuentra internado en un hogar en la ciudad de New York. Ha llegado desde Argentina hace una semana y no recuerda nada de su pasado: vive, congelado e impedido para moverse por sus medios, en un presente total. La novela irá revelando poco a poco que Ramírez ha estado preso en la Argentina bajo el gobierno de facto debido a su militancia sindical, que durante su encierro han asesinado a toda su familia y que de algún modo ha logrado salir del país gracias a la ayuda de organismos de derechos humanos. El otro personaje es Larry, un profesor de historia, comunista, ahora desocupado, que Ramírez contrata para que lo saque a pasear en la silla de ruedas un par de veces por semana y del cual espera aprender todo lo que ha olvidado. Como señala Jorge Panesi, la historia de Larry está igual de "congelada" que la de Ramírez; su historia es también una historia de impedimentos y fracasos: una familia desmoronada que lo echó del hogar apenas pasada la adolescencia, un matrimonio fracasado que todavía no puede superar, y una carrera abandonada lo dejaron sobreviviendo en la desidia. La marginalidad lo lleva a encontrarse con

\footnotetext{
1 Respiración artificial, de Ricardo Piglia, es del mismo año pero elige como estrategia la alegoría y la elusión (PÁEZ, 1995, p. 106). El epígrafe que la antecede, de T. S. Eliot, delata el núcleo común que hermana a ambas novelas y obliga a leerlas en constelación: la pérdida de la experiencia. "We had the experience but missed the meaning, an approach to the meaning restores the experience" (PIGLIA, 2013, p. 9).
} 
Ramírez, ese otro marginal que le devuelve su rostro vacío. “La enorme parálisis de horror situada en Argentina puede revelar las zonas de parálisis del otro país y la otra cultura" (PANESI, 1998, p. 156).

Ramírez "no recuerda su pasado de resistencia en la Argentina, pero tampoco el significado de los afectos, sobre todo de los afectos familiares (es un amputado afectivo), e ignora, como un niño, los resortes de la vida sexual" (PANESI, 1998, p. 157). Es un niño viejo que debe aprender de nuevo el mundo. Su pasado ha quedado en un período prehistórico bloqueado por la represión. La palabra es ambivalente y esa ambivalencia está en el origen del trauma: la represión psíquica como defensa ante la represión, literal, del estado de la que ha sido víctima. No solo debe aprender el mundo sino que además, y sobre todo, debe aprender cómo hablarlo pues, junto con la memoria, ha perdido

La imposibilidad de la lectura: el lenguaje. Está suspendido en una extraña afasia: sabe hablar pero las palabras han perdido, para él, su sentido: "estuve muy enfermo, en mi país. Me acuerdo de todas las palabras [...] Sé lo que significan, leí la definición en el diccionario, pero tal vez no las haya experimentado últimamente. Y por eso entiendo el significado... hasta cierto punto, nada más (PUIG, 2010, p. 8).

Se trata de una mudez particular: habla, pero sus palabras no pueden más que inquirir por su propio sentido olvidado ${ }^{2}$. Cuando Freud (2013) analiza los pequeños olvidos de palabras y nombres en la vida cotidiana, los atribuye a las conexiones de estos con pensamientos reprimidos. Así, la dificultad para recordar algún nombre puede derivar de la asociación de esa palabra con alguna vivencia traumática. El olvido de Ramírez podría pensarse como la hiperbolización extrema de este mecanismo: aquello reprimido -el recuerdo de la muerte de la familia- es tan inmenso que no hay palabra que no se le pueda asociar. Es el lenguaje mismo el que no puede hablar sin referirse a ello y esta imposibilidad de no decir, porque cualquier cosa que se diga nombrará la tragedia, se transfigura en la imposibilidad de decir, estrategia negatoria que escapa de un trauma imposible de elaborar borrando las vías

2 La crítica se ha dedicado a leer Maldición eterna a quien lea estas páginas casi exclusivamente desde la problemática de la traducción, que está en la génesis de la novela pues fue escrita en inglés a partir de las notas tomadas de la conversación de Puig con un hombre que conoció en New York. Creemos, sin embargo, que es un error interpretar el problema de Ramírez como un tema de traducción y de exilio pues desde las primeras páginas Puig se encarga de aclarar la dimensión de la afasia de Ramírez, que excede lo idiomático: "Señor... Larry. Yo sé inglés, sé todas las palabras. En francés, en italiano, sé las palabras. En castellano, mi lengua original, sé todas las palabras pero..." (PUIG, 2010, p. 8) 
a su acceso. Cuando todo lo que hay para decir sobre sí es el horror, las palabras mismas devienen horrorosas. De esta manera, Ramírez repite en el lenguaje la pérdida que ha sufrido. "Solo bloqueando [su historia] y produciendo en sí mismo la misma aniquilación que un sistema represivo llevó a cabo con su propia familia, de alguna manera, 'sobrevive"' (PÁEZ, 1995, p. 113).

Al comentar un pasaje de los ensayos de Montaigne en el que este cuenta cómo se vio al borde de la muerte luego de un accidente de caballos, Agamben afirma que la muerte es ese "límite último que

Leonardo

Berneri puede alcanzar nuestra experiencia", una experiencia "de lo inexperimentable" (AGAMBEN, 2007, p. 51), una experiencia que no le pertenece al sujeto. En este episodio Montaigne anticipa, según Agamben, la idea de inconsciente del psicoanálisis, que colocará no ya en la muerte sino en la infancia ese momento donde ocurre la experiencia de lo inexperimentable, "el mysterion que todo hombre instituye por el hecho de tener una infancia" (AGAMBEN, 2007, p. 71). Muerte e infancia adquieren una relación sinonímica. La cercanía de la muerte -la propia, en el encierro y la tortura, pero sobre todo la de su familia- ha devuelto a Ramírez a una nueva infancia: con una historia perdida en la inefabilidad, Ramírez ha dejado toda su vida anterior en una etapa prelingüística. "Lo inefable es en realidad infancia”, afirma Agamben (2007, p. 71), ese momento en que lo humano y lo lingüístico no se corresponden.

Perdida la experiencia, es como si el lenguaje hubiera perdido su espesura y ahora solo quedara la sospecha de que debería ser algo más que lo que es. Desde esa sospecha Ramírez lee. En la disponibilidad ociosa que le otorga la internación, Ramírez lee compulsivamente y memoriza definiciones y datos, acrecienta su vocabulario. Se trata de una lectura atrofiada. Al perder el sentido de las palabras, ha perdido también la capacidad de leer y solo lee diccionarios y enciclopedias, de los que pretende, memorizando datos, obtener el sentido del mundo. Su lectura es la negación de la lectura, es la lectura representada en su imposibilidad. Cuando Ramírez lee ficción, la lee antropológicamente, se limita a buscar en los textos los rastros, hábitos y modos de una cultura: "tal vez me equivoque, y sea solamente en Navidad que se espera hasta cierto momento para abrir los regalos... ¿ $\mathrm{O}$ es para los cumpleaños? Fue una de las primeras cosas que leí cuando llegué al Hogar... era en una novela..." (PUIG, 2010, p. 110) Esa atrofia de la lectura halla su correlato en la inmovilidad física en la que se encuentra el viejo, postrado en su 
silla de ruedas y en la cama. Triplemente impedido - por la voz, por la memoria y por el cuerpo -, solamente cuenta con sus revistas y enciclopedias y con Larry, su compañero en los días del destierro.

Pero no hay cuerpo que no tenga huellas o que no sea él mismo huella de algo. La "mudez" del viejo -esa habla plana, carente de sentidos- dice algo, nombra un misterio que se verá intensificado cuando lleguen por correo, enviados por una oficina de derechos humanos de Buenos Aires, unos libros que le pertenecieron. La aparición de los libros lo cambia todo. Se trata de tres novelas francesas: Les liaisons dangereuses, La princese de Cléves y Adolphe (hay una cuarta novela, de la que nunca se dice el título); Ramírez no las reconoce como suyas pero llevan su nombre escrito. Enseguida Larry descubre que hay algo extraño en ellas. “¿Qué son estos números encima de las palabras? Parecen no seguir ningún orden. 32, 1, 3, 16, 5, 12, 4...” (PUIG, 2010, p. 111).

Con el descubrimiento de esos libros y del pasado que encierran - porque, pronto lo descubrirá, esos números son el código en que se encuentra escrito un mensaje del viejo -, los sueños de Larry de convertirse en investigador y volver a la vida académica se reaniman. Una vez que descifre la clave interpretativa de las anotaciones, Larry espera poder elaborar lo que Benjamin llama la "experiencia histórica auténtica" o la "experiencia en el sentido propio del término", en la que "ciertos contenidos del pasado individual entran en conjunción en la memoria con elementos del pasado colectivo" (BENJAMIN, 2001, p. 10). Se cumpliría de esta manera su sueño de regresar a la vida académica y de salir de la situación de lumpenaje en la que sobrevive, a la vez que realizaría una acción políticamente significativa. Larry “volvería a restaurar por el lenguaje la experiencia perdida [de Ramírez], condición indispensable para la existencia, a su vez, de la historia, como memoria pública en un lugar y en una época dados" (PÁEZ, 1995, p. 113).

Los libros motivan a Larry a responder la demanda de ese rostro ${ }^{3}$ sin historia e intentar develar los secretos de esa vida expropiada de sí. Para Lévinas, el pasado es "la huella (trace) de aquella realidad que me

3 Cf. Lévinas (2002, p. 227-228): “es mi responsabilidad frente a un rostro que me mira absolutamente extraño [...] lo que constituye el hecho original de la fraternidad [...] Escuchar su miseria que pide justicia no consiste en representarse una imagen, sino ponerse como responsable, a la vez como más y como menos que el ser que se presenta en el rostro. Menos, porque el rostro me recuerda mis obligaciones y me juzga. El ser que se presenta en él viene de una dimensión de altura, dimensión de la trascendencia en la que puede presentarse como extranjero, sin oponerse a mí, como obstáculo o enemigo. Más, porque mi posición de yo consiste en poder responder a esta miseria esencial de otro, en descubrirme recursos". 
Leonardo

Berneri

convoca y apela a la responsabilidad" (MÈLICH, 1997, p. 179). Ramírez significa para Larry la oportunidad de "la salida del letargo de la existencia y del ensimismamiento del existir. El otro significa la ruptura de [su] soledad y la posibilidad de que el presente tenga futuro" (MATE, 1997 apud MÈLICH, 1997).

Las fervientes lecturas adolescentes de textos religiosos y teológicos, su formación filosófica y política (Marx, Hegel, Sartre, Camus) en busca de un vocabulario "para darle nombre a todo lo que iba descubriendo" (PUIG, 2010, p. 133) y sus estudios en la universidad hicieron de Larry un lector inteligente y suspicaz. Al igual que para Ramírez, la lectura está ligada a la vida de Larry de forma constitutiva. Tal como lo señala Cisterna Gold (2011, p. 49), "Larry comienza su autobiografía en el mismo momento que se inicia su interés literario, su interés por la lectura":

Recuerdo cuando empecé a leer, el goce que me dio (...) Me devoraba los libros después de la escuela (...) Enseguida empecé a leer cosas por mi cuenta. Filosofía. Teología, cuanto más arrevesado el libro mejor. Me gustaban especialmente las frases largas y complicadas, con referencias a referencias de referencias. El tema no importaba, era el movimiento que adquiría, la lógica, la belleza, la arquitectura complicada, la estética, que me daban placer. Supongo que lo que estaba emergiendo era mi capacidad de gozar (PUIG, 2010, p. 131-132).

El psicoanálisis y en menor medida el marxismo, esas "grandes estructuras interpretativas" (PANESI, 1998, p. 157), dominan el relato autobiográfico de Larry y su interpretación de los hechos de su propia vida y de la de Ramírez. Esas estructuras interpretativas lo "interceptan e inmovilizan" (PANESI, 1998, p. 157) con su aplacadora coherencia que le permite otorgar una causa y un sentido a todo. Esto, que en lo político le permite encausar sus energías dispersas en un propósito definido ${ }^{4}$, en lo biográfico funciona como una anestesia. Para cada evento del pasado de su biografía, Larry tiene una interpretación tranquilizadora prove-

\footnotetext{
4 "Fue en los últimos años de la carrera que me interesé en el marxismo [...] Por fin una teoría que daba base, y hasta una explicación a todo el odio, el resentimiento y rebeldía que sentíamos, por nuestra sociedad [...] Era regocijante, liberador. Me sumergí en mis estudios, con un apetito voraz. Era como si a una parte mía confusa y balbuciente se le hubiese dado un lenguaje para expresarse. Todavía sigue siendo parte integrante mía" (PUIG, 2010, p. 202).
} 
niente de "ese sistema suyo de psicoanálisis sintético" (PUIG, 2010, p. 149), tal como se le burla Ramírez. Larry se contenta con encuadrar su derrotada historia familiar y amorosa en el relato psicoanalítico y encuentra allí un lugar confortable desde el que enunciarse con impasibilidad: "soy culpable de desear a mi madre, de querer quitársela a mi padre, de no importarme por la suerte de él, de echarlo a la calle, de abandonarlo, de lo que sea, con tal de apartarlo para siempre, alguien a quien también amé mucho, pero que lo mismo quise destruir" (PUIG, 2010, p. 143).

Ramírez alcanza a notar que el psicoanálisis no es más que el velo discursivo con que Larry oculta aquello que no puede entender: "A la menor insinuación usted sale con ese cuento. Está siempre listo para repetir lo mismo, ya tiene las frases hechas" (PUIG, 2010, p. 143-144).

La imposibilidad de la lectura: Luego agrega: "cuenta esa historia [la del complejo de Edipo] para tapar otra cosa mucho peor (...). Tal vez sea mejor tener esa sensación de vergüenza que ninguna otra. Tal vez usted no sea capaz de sentir nada, nada en absoluto. Y eso le da más miedo que todo lo demás" (PUIG, 2010, p. 225). Hay otros momentos, sin embargo, en los que Larry abandona sus estructuras interpretativas y se libra al devenir a la palabra: son los diálogos conjeturales en los que ambos personajes fantasean con escenarios de ficción y en los que improvisan un teatro dialogado. Es un ejercicio de composición colectiva a través del cual se inventan tramas en las que se exponen solapadamente los traumas y las preocupaciones de las vidas de esos personajes en estado de creación. Cuando están hablando sobre Dios, por ejemplo, e imaginan cómo sería un día en su vida y la de su hijo, la conversación rápidamente entra en un estado de indeterminación en donde se mantiene la imaginación inventiva (narrar la cotidianeidad de Dios) y se habla, a la vez, de la propia vida (Ramírez pregunta por Dios y Larry responde hablando de su padre):

\footnotetext{
-¿Usted se imaginó a Dios con la cara de alguien ya conocido?

-Tenía ojos celestes. A veces la mirada resultaba dura y fría (...) Lo queríamos pero no lo entendíamos. Lo queríamos mucho, pero nos defraudó (...) Tal vez si me hubiese llevado a alguna parte, solos, sin mi madre, a algún lugar nuevo, donde sentirnos bien juntos, y si hubiese compartido más de sí mismo, todo habría sido más fácil (PUIG, 2010, p. 140-141).
} 
Aunque el juego es siempre impulsado por Ramírez, cuando Larry cede al flujo del fantaseo, deja aparecer sus fantasmas, y librado de la explicación aplacadora, se muestra en el auténtico desamparo en el que vive. Él es también, después de todo, alguien despojado: despojado de su familia, despojado de un proyecto de vida, de amores, despojado también de su pasado por los mecanismos del poder que le han arrebatado su apellido, Giovanangelo, marca de la extranjería, para otorgarle el de John: pequeño trueque a través del cual su abuelo inmigrante cedió su historia a cambio del nombre genérico que habilitaba la posibilidad de una pertenencia. La Leonardo ficción, ese monstruo generado en el sueño de la razón, aparece como el Berneri territorio al que el logos no puede arribar, y su vértigo, cuando roza las zonas escabrosas de la historia de Larry, lo hace víctima, en palabras de 434 Panesi (1998, p. 158), "del ahogo y de la asfixia": "me suena sofocante. No quiero vivir ahí"' (PUIG, 2010, p. 86), dice Larry cuando Ramírez le inventa la imagen de una vida de matrimonio con la enfermera del Hogar.

Solo en la dimensión onírica del discurso librado a la deriva de la ficción la potencia inquietante y todavía en acto del pasado biográfico se deja sentir. El remedio ficcional funciona para ambos a un mismo tiempo. En estas ficciones, que a veces son creadas entre ambos pero otras veces son diálogos imaginados solo por el viejo, entendemos que Ramírez ve en Larry al fantasma del hijo que le reclama por su muerte. La ficción alucinatoria -Ramírez no distingue qué diálogos ocurren realmente y cuáles imagina - le permite saldar conjeturalmente una deuda imperdonable y otorgarle al hijo muerto la posibilidad de una venganza que equilibre el pasado:

\footnotetext{
El viejo no había muerto, estaba herido solamente [le dice Ramírez a Larry] Lo que usted tiene que hacer es de inmediato echar las manos al cuello del enemigo y estrangularlo. Presione, él no tuvo ninguna piedad con usted, él quiso reventarle los ojos, húndale ahora esos dedos jóvenes de usted en la piel fláccida y maloliente (PUIG, 2010, p. 99).
}

En El beso de la mujer araña, otra de las novelas "de parejas" de Puig, al igual que en esta, se narraba la historia de dos personajes en conversación y también en ella la lectura jugaba un papel fundamental. Se trataba de los relatos de las películas que Molina le contaba a Valentín, a partir de los cuales entraban en disputa dos modos de lectura: 
una exegética, encarnada por el guerrillero, que consistía en analizar ideológicamente el sentido de los films y otra que podríamos llamar vital, encarnada por el homosexual, que consistía en suspender el juicio acerca del sentido y conjugar el relato del texto ficcional con el relato de la propia vida, en un juego de identificaciones y de reescrituras a través del cual el personaje lograba construirse a sí mismo en la mezcla de literatura y vida. No se trataba de una lectura bovarista que buscara imitar el arte, sino de algo más complejo: leer el arte desde la propia vida y entender la vida a través de la experiencia de la lectura, sin que ninguno de los dos movimientos preceda al otro. Es el mismo modo de lectura que practicaba Toto, el personaje de la primera novela de Puig, La traición de Rita Hayworth, que narraba su vida de tedio, opresión y miedos a través del relato alucinado de las películas que veía con su madre. En El beso... se muestra cómo Molina educa a Valentín en su modo de lectura: ese lector cerebral, crítico e inteligente acaba descubriendo que la lectura es un acontecimiento indeterminado que sucede antes de que las categorías teóricas entren en juego, antes de que la pulsión hermenéutica estabilice los poderes de conmoción del texto.

Podría pensarse que, en lo que respecta a los modos de lectura, Larry vendría a ocupar el lugar que ocupaba Valentín en El beso... Larry sería ese "arrogante hermeneuta" (PÁEZ, 1995, p. 111) cuya lectura no es sino una ocasión para la interpretación (LITTAU, 2008, p. 19) - de allí su interés por textos teóricos antes que narrativos y su proyecto de convertirse en investigador -, que se vería transformado por la insistencia del otro personaje. Sin embargo, el esquema se rompe antes de que podamos esbozarlo. Desde un principio, el discurso de Larry acerca de su iniciación en los libros postula la lectura hermenéutica ligada al goce. Esto es algo heterogéneo a la representación negativa del lector hermeneuta que se puede ver en la literatura anterior de Puig: el inicio de la lectura coincidiendo con el inicio de la "capacidad de gozar" (PUIG, 2010 , p. 132). Larry encuentra en el desafío intelectual que le plantea un texto un goce que va más allá de la preocupación por comprender. El sesgo estereotípico con que estaba elaborado el personaje de Valentín se diluye con este otro personaje que muestra la multiplicidad de posibilidades de la lectura. Larry rompe los esquematismos de los discursos sobre los lectores al mostrar que un lector es, en realidad, varios lectores y que una lectura es, antes que algo estable, una pugna entre fuerzas heterogéneas. 
Es reveladora, en este sentido, la lectura que hace Larry de Camus. Cuando leyó El extranjero, le cuenta a Ramírez, comenzó a soñar con vivir junto a su mujer en Argelia para disfrutar de "los espacios abiertos, y el sol abrasador, y la gente bronceada con que [se] encontraría" (PUIG, 2010, p. 168). Sin embargo, tiempo después, comprende el sentido "real" del texto y se le acaban los sueños al enterarse de que Camus "estaba hablando de una colonia" (PUIG, 2010, p. 168) y que "la gente joven y bronceada era europea, gente odiada y a un paso de ser expulsada" (PUIG, 2010, p. 168). La fuerza de la lectura vital más eleLeonardo mental (querer vivir lo que se lee) convive agónicamente con la fuerza Berneri de la lectura interpretativa: no se trataba de un relato idílico.

En su biografía de lector, Larry acaba convirtiéndose en un lector hermeneuta, que solo lee para estudiar, su "cerebro clasifica y asocia el material" (PUIG, 2010, p. 201), y cuando lee novelas se siente culpable "porque es una lectura que no conduce a nada" (PUIG, 2010, p. 196). Pero en el fondo del acto de leer, sosteniéndolo, sigue hallándose el goce. "Nos íbamos [con la novia] con una canasta de picnic, al parque [...] Charlábamos, y nos besábamos, dábamos caminatas, nos leíamos pasajes mutuamente" (PUIG, 2010, p. 166): Larry, el lector intelectual, es capaz de repetir la escena de lectura romántica por excelencia. La lectura - hermenéutica o no - aparece en su misterio, como un acontecimiento indeterminado y no como el objeto de una didáctica. La metáfora de la bibliofagia - "me devoraba los libros", estudiaba con un "apetito voraz" -, típicamente ligada a la representación de la lectura pasatista (RADWAY, 1986), es utilizada en la novela para referir la experiencia de la lectura árida de los textos complejos que desafían intelectualmente al lector, experiencia que se nos muestra, por primera vez en Puig, como apasionante. El didactismo en que la lectura aparecía ficcionalizada en El beso de la mujer araña (a través del cual se atacaba las lecturas que interpretan la cultura de masas exclusivamente en términos de alienación) es superado y retorna, ampliada, la auténtica interrogación por aquello que acontece en el acto de leer. La lectura hermenéutica - parece decir - quizá no se distinga absolutamente de otros modos de lectura $y$, aunque la vía intelectual fracase al intentar comprender las contingencias de esas vidas fragmentadas, es también una respuesta a la necesidad de significar la propia existencia y tiene un rol que cumplir cuando lo que se juega en el sentido de un texto es la posibilidad de recuperar la experiencia atrofiada de 
un sujeto y de una comunidad entera atravesada por el trauma de la violencia política: porque, desde la llegada de los libros, la obsesión de Larry será descifrar ese código y el mensaje que encierran porque sabe que en eso se juega no solo el pasado del viejo sino también la historia política de un país.

"Si se va buscando los números, por orden, se va armando una frase" (PUIG, 2010, 111). Larry descifra el código de las marcas que Ramírez dejó en los libros y descubre que allí, encriptadas, se encuentran las cartas que este escribía a su familia desde la cárcel y también las que recibía de ellos y los guardias le quitaban, transcriptas para no olvidarlas en una suerte de diario personal. El mecanismo de encriptación es simple pero suficiente para sortear la mirada vigilante y se podría entender como una literalización extrema del modo de lectura típico de

La imposibilidad de la lectura: los personajes de Puig, cuyo prototipo es Toto. Al igual que Toto, Ramírez recurre al texto no para comprender su sentido sino para hallar en él las palabras que habiliten un modo de nombrarse a sí mismo en un relato. Ramírez es Toto llevado a un extremo absurdo por la mecanicidad del procedimiento: selecciona palabras de las novelas y las ordena, numerándolas según su necesidad, para escribir. "Aquí el personaje de la novela se refiere a 'grève' como arenal, pero usted usa el otro sentido de 'grève', ¡huelga!” (PUIG, 2010, p. 112).

Se trata de una lectura doblemente irreverente: irreverencia profanatoria hacia el texto, que queda olvidado como construcción que exige cierta lectura y pasa a ser mero instrumento de un código nuevo (sin embargo, ¿no sigue diciendo algo la elección de las novelas de las que extrae las palabras? ¿Cuáles son esas relaciones peligrosas que amenazan al lector?, ¿las de la militancia?, ¿de la familia?) e irreverencia hacia el ojo vigilante del aparato represivo estatal que lo mantiene en confinamiento y que se ve burlado por la treta del prisionero.

El desciframiento reanima en Larry la pasión por la investigación y - utopía del intelectual - el interés por llegar a lo político desde la academia. "Quiero anotar todo este material... Podría ser un documento importante, de resistencia a la represión [...] Podría ser material útil para mí... para comentarlo. Escribir algo" (PUIG, 2010, p. 112). Diario personal y antología de cartas, el texto encriptado en las novelas es, efectivamente, un documento de memoria, un sofisticado artilugio lingüístico destinado a burlar los controles policíacos y a subsistir a la censura. Larry sospechaba ya el pasado militante del viejo ya que sabía que 
su llegada a los Estados Unidos se había debido a la intervención de un Comité de Derechos Humanos y a la sintomática aversión del viejo por la política: "les tengo un profundo desprecio [a esos asuntos]" (PUIG, 2010, p. 48).

Los mensajes encriptados revelan, finalmente, que antes de ser secuestrado Ramírez había sido un abogado laborista que, haciendo frente, en palabras de Larry, "a una entera maquinaria represiva" (PUIG, 2010, p. 141) y a la burocracia sindical, había coordinado "huelgas salvajes... en seis plantas automotrices" (PUIG, 2010, p. 179). Las noLeonardo velas revelan, además, lo que las ficciones inventadas por el viejo ya Berneri dejaban adivinar, es decir, "una vida y su fracasada relación con sus hijos y su esposa" (CISTERNA GOLD, 2011, p. 55). Según la lectura que 438 Larry logra realizar, Ramírez se había compenetrado tanto con su trabajo y su compromiso político que se desentendió "de su esposa e hijos, y de las carencias diarias de ellos, de los reclamos de ellos" (PUIG, 2010, p. 143). En el diario que cifran los libros, aparece transcripta una carta que el hijo le escribió y que le hizo dar cuenta a Ramírez de que se había convertido en una carga asfixiante e insoportable para su familia. Se lee también la resignación con la que asume que si muriese les haría un bien a su esposa y su hijo; sin embargo, es la muerte de la familia la que llega justo en ese momento crítico de renuncia, como una burla del destino. "A ellos los mataron, a su esposa, a su hijo; y a la pobre francesa que subía y bajaba el telón [la pareja del hijo]. Bastó con poner una bomba en su casa" (PUIG, 2010, p. 236).

La novela familiar del psicoanálisis con que Larry se explica esquemáticamente su vida adquiere en Ramírez una dimensión visceral y trágica al ser catalizada por la violencia política. Tal como lo define Eduardo Grüner (2002, p. 31), "lo trágico es, justamente, lo que excede la capacidad de simbolización discursiva pero al mismo tiempo la determina, en un choque perpetuo e irreconciliable entre el discurso y algo del orden de lo real". No es solo lo familiar lo que está en el origen del trauma, es lo familiar cruzado por lo político y que hace de Ramírez ese sujeto impedido. Ramírez es como un personaje de tragedias griegas, es una Antígona, situada en el cruce irresoluble entre el oikos y la polis.

La violencia de lo acontecido borró la memoria del viejo y lo dejó sin pasado pero algo, irrebatible, todavía permanece y es la culpa. Este es el nudo del trauma: Ramírez no puede dejar de asumir la carga del horror y se atribuye la responsabilidad por la muerte de su fami- 
lia. "El objeto a que está dirigida [la culpa] ha desaparecido y el acto original está olvidado pero la culpa se extiende sobre su vida como una mancha de aceite" (PUIG, 2010, p. 150), le dice Larry. El asunto vuelve en cada una de las ficciones que Ramírez inventa. En uno de los relatos dos perros lo salvan de unos hombres que quieren matarlo y él concluye: "se sacrificaron para que yo pudiera vivir..." (PUIG, 2010, p. 156). En el sueño de la Rusia zarista las palabras de Larry resuenan fantasmales:

- Gracias... señor, usted trabajó muy duro en su profesión, ¿no La imposibilidad es así? Fue muy empeñoso, diligente [...] Pero llegó el momento de la lectura: en que empezó a querer a su trabajo, ya no le resultaba doloroso [...] Es bueno trabajar, pero lo bueno puede volverse peligroso, puede seducirnos. Porque es bueno y redunda en logros, en conquistas, y porque se está desarrollando una tarea socialmente válida, la mente aprovecha así para desentenderse de otros quehaceres dolorosos o difíciles.

-¿Por ejemplo cuáles?

-Se sacrifica la familia en nombre del trabajo.

- ¿Y ese sería mi caso? (PUIG, 2010, p. 209).

Pero en la ficción, Ramírez ha hecho todo para salvarle la vida a Larry y a su prometida, por lo que la voz onírica, reparadora, del joven puede responderle, tranquilizándolo, dándole la respuesta que nadie puede darle en la vida real, "usted es el ejemplo de lo opuesto" (PUIG, 2010, p. 209).

En uno de esos diálogos en los que se entretejen las memorias de la vida familiar y amorosa de Larry con los inventos de Ramírez, Larry se las ingenia para colar el tema de la actividad sindical y obtiene una fugaz prueba de que, en algún sitio de la memoria del viejo, algo todavía se conserva. El Larry del relato imaginado tiene que organizar una huelga y no está seguro de si funcionará su plan de parar dos horas por día cada sección de manera coordinada. Es ahí cuando se abre el pasaje $y$, como si otra voz hablara desde su boca, Ramírez, que hasta entonces, consternado, había intentado persuadir a Larry de que mandara a otra persona a la fábrica, se despoja de su ignorancia aniñada, de su senilidad, y dice: 
No es dos horas por día, Larry, tan solo dos horas dos veces por semana sería suficiente. Lo que cuenta es cuándo parar cada sección. Tiene que ser hecho de manera que desarticule totalmente el plan de producción. Escuche, un programa de producción sigue una concatenación lógica, es esa concatenación que debemos atacar... Las piezas de una determinada sección no serán retiradas a tiempo, se apilarán y saturarán la línea de ensamblaje. Otro ejemplo: si los ejes no llegan a tiempo el resto de la operación montura también se detiene (PUIG, 2010, p. 186).

Leonardo

Berneri

Sumido en el discurrir de la ficción, Ramírez recupera el espesor perdido de las palabras. Es, otra vez, quien había sido antes de la 440 cárcel. Sin embargo, lejos de devenir en una revelación reparadora, el rapto de pasado se va así como llegó y la represión se reafirma cada vez que Larry le lee pasajes de las anotaciones encriptadas: "está todo tergiversado, siguiendo su antojo. No sé qué tipo de necesidad estaba usted satisfaciendo al hacer tal cosa. Cambiar un texto entero" (PUIG, 2010, p. 235), protesta Ramírez. “Recordar es exponerse a la desesperación: y el tiempo pasado del verbo ser no da por sentada otra cosa que la realidad de la muerte" (STEINER, 1980, p. 47). El rapto de memoria inducido por la imaginación dialogada no dura más que lo que dura la frase y no volverá a ocurrir, enseguida regresa la culpa y la necesidad de inventarse un destino alternativo en la nebulosa zona de la ficción:

Dígame por qué está decidido a ir a ese mitin... a pesar del peligro terrible [...] Larry, no estoy seguro de haber comprendido... No estoy convencido del todo... En este momento no se me ocurre ninguna razón que pueda justificar su muerte... Lo único, lo que viene primero para sus seres queridos... es que usted siga vivo... Nada podría tener más importancia (PUIG, 2010, p. 188).

En la decodificación de los libros - multiplicidad de textualidades, palimpsesto de lecturas - la Historia misma, esfíngica, se asoma con su incógnita. Pero toda teorización está condenada a fracasar en la literatura de Puig y esto no ha cambiado. Aunque en esa cruzada interpretativa contra unos signos manuscritos en páginas de novelas olvidadas algunos de los datos de los hechos pasados se recuperen, la memoria, estallada en fragmentos de olvido, sigue siendo una apuesta perdida. La 
posibilidad de construcción de un relato coherente y explicativo a partir de la experiencia del horror permanece vedada: los hechos nunca escapan de la condición de clandestinidad y secreto en la que ocurrieron y es el mismo Ramírez el que se encarga, en sus últimos momentos de vida, de negarle a Larry la posibilidad de acceder a los libros y realizar la investigación. La vida del viejo se irá tan enigmática como llegó a esa tierra ajena, negando cualquier esperanza de recuperación de la experiencia perdida, pero su pregunta quedará resonando: ¿qué es lo que debería sentirse ante las palabras? La escritura del pasado, el trabajo de la historia, no alcanzan a resistir una pregunta para la que no hay respuesta. Habremos de convocar el nombre de Walter Benjamin para pensar la literatura de Puig, para pensar la estrecha relación que une en Ramírez la imposibilidad de la experiencia y el vacío del lenguaje. La idea aparece en "El narrador" y en "Experiencia y pobreza":

\footnotetext{
La cosa está clara: la cotización de la experiencia ha bajado y precisamente en una generación que de 1914 a 1918 ha tenido una de las experiencias más atroces de la historia universal. Lo cual no es quizá tan raro como parece. Entonces se pudo constatar que las gentes volvían mudas del campo de batalla. No enriquecidas, sino más pobres en cuanto a experiencia comunicable. (BENJAMIN, 1987, p. 167-168)
}

De la intensidad de ese escenario que había llevado la muerte a una escala hasta entonces inimaginada, el hombre, que ha pagado su entrada "en el tiempo del sujeto moderno [...] sacrificando el antiguo concepto de experiencia" (FORSTER, 2012, p. 131), no ha podido elaborar un relato que transforme lo vivido en narración porque no hay relato posible que conjure el encuentro con la muerte. El horror, leitmotiv de los nuevos tiempos, como negación de la experiencia, exige el silencio o la literalidad: cada vez que acontece el horror, surge la hesitación entre la memoria y el silencio. Después de la Segunda Guerra Mundial, la literatura se debatió entre la imposibilidad de escribir (cómo escribir poesía después de Auschwitz, se preguntaba Adorno) y el imperativo de la memoria que clama recordar para no repetir. El viejo Ramírez representa la imposibilidad del testimonio y es la contracara de un Primo Levi. No hay relato que construir del horror. Solo resta, para él, intentar aprenderlo todo otra vez. 
La novela, escrita cuando todavía miles de desaparecidos permanecían en la sala de torturas, se adelanta a ese problema que marcaría al país en los años subsiguientes al fin de la dictadura: la cuestión de la memoria. No podemos dejar de leer, desde hoy, Maldición eterna... en esta tensión irresoluble entre la imposibilidad del recuerdo, representado por Ramírez, y el deber de memoria (VEZZETI, 2007, p. 3), encarnado en la figura de Larry y su insistencia en recuperar los trozos quebrados del pasado. Anticipa, así, una pregunta que inaugura una temporalidad dislocada: la pregunta por aquello que queda después del final,

Leonardo

Berneri aquello que persiste, que resta, luego de ese acontecimiento final que es el crimen dictatorial y el fin de los sueños emancipatorios ${ }^{5}$. En el tiempo abierto por la pregunta se hace presente un futuro definido por la pregunta por el pasado.

Ramírez, lo decíamos antes, es un personaje de tragedia griega: muerto en vida, ha pagado a Caronte su ingreso al subsuelo de la muerte a un alto precio y ha bebido de las aguas del Leteo para ser expulsado luego a la superficie como un invocado al que las palabras inscriptas en un libro y leídas por un piadoso Odiseo reclaman. Porque, como Odiseo, Larry se asoma a las puertas del Hades y realiza su nekyia, su invocación a los muertos, para intentar entender qué ha sido de ellos. La lectura como nekyia encuentra su fórmula poética en aquel verso de Quevedo, rescatado por Chartier (2012): escuchar a los muertos con los ojos. En los libros rescatados en los que Ramírez supo encriptar su escritura, Larry oye esa voz de ultratumba ahora usurpada. Pero no es la experiencia perdida lo que aparece sino el abismo, la certidumbre de que allí hay algo inalcanzable, incomprensible y - lo que la existencia afásica del viejo denuncia - insoportable. Muerto en vida, Ramírez es, también, un zombi. ¿No es la muerte, acaso, la que ha dejado a Ramírez en ese estado de suspensión? Como salido de una película de George A. Romero, el viejo es uno de esos seres que deambulan instintivamente por los lugares en los que vivieron para intentar la repetición imposible del eco de lo vivido: para Ramírez, esos lugares -ya que no pueden ser

5 Mariana Catalin (UNR-CONICET) trabaja actualmente los Imaginarios para después del final en la narrativa argentina actual. De los trabajos que se desprenden de ese proyecto -el último de los cuales es "Un final/el final: Cuaderno de Pripyat de Carlos Ríos". Anclajes. Revista del Instituto de Investigaciones Literarias y Discursivas, XXII(2), mayo-agosto de 2018, p. 21-34-, tomamos la idea de un "después del final" como un modo de la ficción de indagar el tiempo que sobreviene a un final de los tiempos, "la posibilidad de narrar un tiempo de la sobrevivencia que deje entrever, sin embargo, un final radical” (CATALIN, 2017, p. 1). 
los geográficos por su condición de exiliado- son los libros, la palabra escrita. "El zombi - afirma Mariana Catalin (2016, p. 14) - supone que el final ya ha advenido, es decir, introduce un tiempo 'post-apocalíptico"'. Desde la figura zombi de Ramírez, Maldición eterna... instaura la dictadura como evento que marca la cesura en el transcurrir de la historia. La dictadura como la gran catástrofe del fin de los tiempos, del fin del tiempo. Pues no hay tiempo en el zombi: pura existencia sin consciencia, el zombi no experimenta nada, es un cuerpo que camina sin pasado ni futuro. La doble edad de Ramírez, a la vez viejo y niño, expresa esta condición: como niño, no tiene pasado, y como viejo, no tiene futuro. Es un cuerpo que persiste en ese tiempo en el que tiempo ha dejado de contar. La frase es de Valéry y remite, otra vez, a "El narrador" de Benjamin, donde se la cita como un lamento por el fin de la época

La imposibilidad de la lectura: premoderna en la que la exigencia de la productividad industrial no regía el ritmo de vida. Ese tiempo remoto era el tiempo en el que el tiempo no contaba y el tiempo postapocalíptico encuentra su reflejo en él. Lo postapocalíptico es, también, un regreso a lo primitivo, algo explorado por las novelas del género, que, sin embargo, lo piensan como tiempo futuro, mientras que Maldición eterna a quien lea estas páginas lo instaura en el presente histórico del momento de la escritura: la dictadura ha dislocado el tiempo y ha dejado esos cuerpos perdidos como símbolos del final.

Maldición eterna... marca un quiebre radical en la novelística puiguiana en lo que respecta al modo de ficcionalizar la lectura. En primer lugar, goce e intelectualidad habían permanecido durante toda la producción literaria de Puig como polos que se excluían mutuamente. En el discurso de Larry sobre su propia práctica de lectura, sin embargo, la lectura como goce surge a la par que el despertar de los deseos eróticos. En segundo lugar, hay un reconocimiento de la necesidad de que la lectura interpretativa ocurra, como gesto de compromiso ético con las preguntas por el pasado. El lector que busca la verdad en el texto ya no es una caricatura a la que educar (como Valentín en El beso de la mujer araña) sino un Sísifo que cumple su deber histórico ante la demanda muda de un otro despojado de relato; aun cuando se trata de una búsqueda que está condenada a fracasar, sigue habiendo necesidad y nobleza en el intento: el proyecto de escritura de investigación a partir de los libros codificados le es arrebatado a Larry de sus manos pero él no ceja en su empeño de conjugar la vida intelectual con el quehacer político. 
Por último, la lectura interpretativa no es el único modo de lectura en la novela que aparece signado por el fracaso. Desde que para Ramírez el lenguaje ha quedado vaciado de su significación al ser golpeado por el peso de la historia, el juego exploratorio y ficcional del discurso que mezclaba lectura y vida para darse un lenguaje auténtico en el que descubrirse a sí mismo, esto es, el modo de lectura típico de los lectores de Puig, también está negado. Ese modo de lectura, el modo de lectura típico de otros personajes de Puig, el modo en que Toto leía, el que Valentín aprendió de las lecciones de Molina, muestra, también,

Leonardo

Berneri su inutilidad. Ramírez, que encontraba en los textos las palabras para hallarse a sí mismo y construirse discursivamente, ya no es capaz, en el exilio, de leer sino maquinalmente. Los delirios ficcionales que ensayan los dos personajes en conversación quizá les (y nos) permitan sentir la vibración de los temblores ocultos del pasado y sospechar el trauma pero no son capaces de revelar una verdad, de solucionar el misterio de una vida atravesada por la violencia de la historia, de ponderar las dimensiones de esa experiencia que apenas se deja vislumbrar, y lo único que logran es acrecentar la fuerza de la incógnita. La lectura no tiene nada que hacer, después de todo, contra aquello que la excede. En este sentido, Maldición eterna... es la narración de una imposibilidad, la imposibilidad de la lectura en cualquiera de sus modos.

Esta es la última lección de Puig. La literatura, cuando no se vuelve pastoral ${ }^{6}$, fracasa en sus respuestas a los problemas que la política y la historia le presentan, pero asume otra labor, acaso irremplazable: los trae a la arena de lo común desde su propia perspectiva indeterminada, habilita abordajes inusitados e intensifica su poder de conmoción.

\footnotetext{
6 Tomamos libremente el concepto de pastoral de Horacio González (2008, p. 163), donde define la lectura pastoral como una lectura fuertemente ligada a lo educacional por la cual "se introduce a un sujeto [...] a un mundo de valores que muchas veces son valores sagrados. Pueden ser valores laicos, pero por detrás, o persiguiendo lo laico de una manera volátil pero efectiva, está lo sagrado". Lo pastoral implica la negación de la crítica y de la reflexión por la fuerza de la moral.
} 


\section{REFERENCIAS}

ADORNO, Theodor. Prismas. La crítica de la cultura y la sociedad. Barcelona: Ariel, 1962.

BACARISSE, Pamela. The necessary dream: a study of the novels of Manuel Puig. Great Britain: University of Wales Press, 1988.

BENJAMIN, Walter. Experiencia y pobreza. En: BENJAMIN, Walter. Discursos interrumpidos I. Madrid: Taurus, 1987. imposibilidad de la lectura:

BENJAMIN, Walter. Sobre algunos temas en Baudelaire. En: BENJAMIN, Walter. Ensayos escogidos. México: Coyoacán, 2001.

CATALIN, Mariana. Amir Hamed: ensayar el final. En: El taco en la brea, n. 4, p. 6-17, 2016. Disponible en: <https://bibliotecavirtual.unl. edu.ar/publicaciones/index.php/ElTacoenlaBrea/article/view/6002/8896>. Acceso en: 7 de mayo de 2019.

CATALIN, Mariana. Restos del desastre o el final como resto: Cuaderno de Pripyat de Carlos Ríos. En: Argus-a, v. VII, n. 26, 2017. Disponible en: <http://www.argus-a.com.ar/archivos-dinamicas/1297-1.pdf>. Acceso en: 7 de mayo de 2019.

CHARTIER, Roger. Escuchar a los muertos con los ojos. Buenos Aires: Katz, 2012.

CISTERNA GOLD, María Inés. Figuras de la autobiografía: La voz del escritor en Maldición eterna a quien lea estas páginas de Manuel Puig. En: Hispanic Journal, v. 32, n. 1, p. 45-59, 2011. Recuperado de: <https://www.jstor.org/stable/44287482>. Acceso en: 7 de mayo de 2019.

FORSTER, Ricardo. Benjamin: una introducción. Buenos Aires: Quadrata, 2012.

FREUD, Sigmund. Psicopatología de la vida cotidiana. En: FREUD, Sigmund. Obras completas: volumen 6. Buenos Aires: Siglo Veintiuno, 2013. 
GONZÁLEZ, Horacio. Políticas de la lectura. En: Alea, v. 10, n. 1, p. 161-171, 2008. Recuperado de: <http://www.scielo.br/pdf/alea/v10n1/ v10n1a12.pdf>. Acceso en: 7 de mayo de 2019.

GRÜNER, Eduardo. La tragedia o el fundamento perdido de lo político. En: BORÓN, Atilio (comp.). Teoría y filosofía política: la recuperación de los clásicos en el debate latinoamericano. Buenos Aires: CLACSO, 2002.

Leonardo LÉVINAS, Emmanuel. Totalidad e infinito. Ensayo sobre la exteBerneri rioridad. Salamanca: Sígueme, 2002.

446 LITTAU, Karin. Teorías de la lectura: libros, cuerpos y bibliomanía. Buenos Aires: Manantial, 2008.

MATE, Reyes. Memoria de occidente. Actualidad de pensadores judíos olvidados. Barcelona: Anthropos, 1997.

MÈLICH, Joan-Carles. El silencio y la memoria. “¿Cómo se puede tocar a Shubert por la noche, leer a Rilke por la mañana y torturar al mediodía?”. En: Ars Brevis, n. 3, p. 171-189, 1997. Recuperado de: <https://www.raco.cat/index.php/ArsBrevis/article/view/93814/142191>. Acceso en: 7 de mayo de 2019.

PÁEZ, Roxana. Manuel Puig. Del pop a la extrañeza. Buenos Aires: Almagesto, 1995.

PANESI, Jorge. Memoria, cuerpo y olvido: Maldición eterna a quien lea estas páginas. En: AMÍCOLA, José y SPERANZA, Graciela (coords.). Encuentro internacional Manuel Puig. Rosario: Beatriz Viterbo, 1998.

PUIG, Manuel. Maldición eterna a quien lea estas páginas. Buenos Aires: Booket, 2010 [1980].

RADWAY, Janice. Reading is not eating: Mass-produced literature and the theoretical, methodological, and political consequences of a metaphor. En: Book Research Quarterly, n. 2, p. 7-29, 1986. 
STEINER, George. Después de Babel. Aspectos del lenguaje y la traducción. México: Fondo de Cultura Económica, 1980.

VEZZETTI, Hugo. Conflictos de la memoria en la Argentina. Un estudio histórico de la memoria social. En: PÉROTIN-DUMON, Anne (dir.). Historizar el pasado vivo en América Latina. Argentina: el tiempo largo de la violencia política. Universidad de Hurtado, 2007. Recuperado de: <http://www.historizarelpasadovivo.cl/downloads/ vezzetti.pdf>. Acceso en: 7 de mayo de 2019.

La

imposibilidad de la lectura: 
